\title{
Evaluation of Different Modalities in Prevention of Seroma Formation Post Modified Radical Mastectomy
}

Mansour Mohamad Kabbash ${ }^{1}$, Abdel-Aal Ali Selem ${ }^{1}$, Anwar A. Elshenawy ${ }^{2}$, Ahmed Raafat Mohamed ${ }^{1 *}$ Departments of ${ }^{1}$ General Surgery and ${ }^{2}$ Onco Surgery, Faculty of Medicine, Aswan University, Aswan, Egypt *Corresponding author: Ahmed Raafat Mohamed, Mobile: (+20) 01002416594, E-Mail: hitmancode@ymail.com

\begin{abstract}
Background: Seroma is an abnormal collection of serous fluid in the dead space of post-mastectomy skin flaps and axilla or following breast-conserving surgery. Seroma is one of the most common early post-operative complications following surgery for breast cancer. Various studies report an incidence ranging from $10 \%$ to $85 \%$ following modified radical mastectomy (MRM) or axillary lymph node dissection (ALND).

Objective: Evaluation of different modalities in the prevention of seroma formation post modified radical mastectomy.

Patients and methods: This was a prospective comparative study carried out in the General Surgery Department, Faculty of Medicine, Aswan University, Aswan, Egypt. in the period between December 2017 and June 2018. Patients scheduled for modified radical mastectomy during the period of study were randomly divided into three groups, mastectomy flap fixation group (10 cases), ipsilateral shoulder immobilization group (10 cases) \& (pre \& post) operative tranexamic acid usage group (10 cases).

Results: Hypertension, obesity, blood transfusion, and bloody field are at high risk of developing seroma after MRM; while DM, cancer stage, number of LN infiltrated and removed don't affect on seroma formation after MRM. Flap fixation was found to be the best modality in the prevention of seroma formation with a low incidence in developed seroma and other complications. On the other hand, tranexamic acid usage pre- and post-operative found that no role in the prevention of seroma formation after MRM.
\end{abstract}

Conclusion: The mastectomy flap fixation technique is a valuable procedure that significantly decreases the incidence of seroma formation, and reduces the duration and amount of drained fluid.

Keywords: Seroma, Modified Radical Mastectomy.

\section{INTRODUCTION}

Seroma is one of the noisiest events that disturb both the patient and surgeon with multiple visits that delay starting the adjuvant therapy and cause great patients' discomfort with the possibility of increased surgical site infection. Seroma is graded 1 if asymptomatic (only diagnosed by ultrasound), graded 2 if symptomatic but can be managed either medically or by simple aspiration, and graded 3 if symptomatic and requires surgical or radiologic intervention ${ }^{(\mathbf{1})}$.

The incidence of seroma has been shown to correlate with certain factors such as obesity, patient's age, breast size, hypertension, presence of malignant nodes in the axilla, number of dissected nodes, early shoulder exercise, and the use of some drugs, i.e. tamoxifen and heparin ${ }^{(2)}$.

Seroma formation increases the risk of postoperative complications; delays wound healing, increases susceptibility to infection, skin flap necrosis, persistent pain, wound dehiscence, and prolonged convalescence ${ }^{(3)}$. There are various methods for preventing seroma, such as prolonged suction drainage, flap fixation, shoulder immobilization, pre $\&$ postoperative use of tranexamic acid, ocreotide usage, dressing compression, tissue sealers ${ }^{(4)}$.

More recent techniques following modified radical mastectomy (MRM) or axillary lymph node dissection (ALND) advocate suturing of axillary or mastectomy flaps to underlying muscle using interrupted polyglactin or dexon sutures placed approximately every $2.5-3 \mathrm{~cm}$ apart followed by placement of drains. These techniques add an estimated 10-20 min to operating time. Techniques of suturing mastectomy and axillary flaps to underlying tissue have been well described and seem to be an efficacious option for the reduction of seroma ${ }^{(5)}$.

Immobilization of the affected arm in the early post-operative period remains controversial. Several authors have been able to show reduced volumes and duration of drainage in patients who immobilize the ipsilateral limb, but this may be associated with shoulder dysfunction ${ }^{\left({ }^{(6)}\right.}$.

Antifibrinolytic agents such as tranexamic acid stops the degradation of the fibrin complexes, thus reducing fluid leakage. Many studies indicated that this mechanism would make more sense in dealing with breast wounds where fluid shows high levels of fibrinogen, while axillary seromas contain lymph-like fluid and thus contain no fibrinogen ${ }^{(3)}$.

\section{AIM OF THE WORK \\ Evaluation of different modalities in the prevention of seroma formation post modified radical mastectomy.}




\section{PATIENTS AND METHODS}

This is a prospective comparative study carried out in the General Surgery Department, Faculty of Medicine, Aswan University in the period between December 2017 and June 2018. Patients scheduled for modified radical mastectomy during the period of study were randomly divided into three groups, mastectomy flap fixation group (10 cases), ipsilateral shoulder immobilization group (10 cases) \& (pre \& post) operative tranexamic acid usage group (10 cases).

\section{Inclusion criteria:}

Patients with breast cancer in the General Surgery Department who underwent modified radical mastectomy with axillary lymphadenectomy extending from the lower border of the axillary vein superiorly down to the fourth intercostobrachial nerve inferiorly and from the medial border of the pectoralis minor muscle medially to the edge of the latissimusdorsi muscle laterally. Patients should have a normal coagulation profile and average body weight.

\section{Exclusion criteria:}

Patients with inoperable breast cancer, Patients who have alterations in blood clotting or immune system, patients on anticoagulant therapy, those with a history of long term use of steroids, patients with uncontrolled diabetes or advanced liver disease, patients with morbid obesity, those with collagen disease and patients who have had previous surgery on the axillary lymphatic system.

\section{Data collection:}

- Demographic data including name, age, sex, residence, occupation, marital status, body mass index, special habits of medical importance, and menstrual history.

- Analysis of the main complaint either a breast lump, mastalgia, or bleeding per nipple.

- History of previous operations especially in the axillary region, chronic diseases.

- Clinical examination including general examination. Local examination was done focusing on the site of the breast mass, size of the mass, and presence of palpable axillary lymph nodes.

- Laboratory (Routine) investigations were done for all patients including complete blood count (CBC), ALT, AST, Urea, Creatinine, coagulation profile, and serum albumin.

- Radiological investigations such as superficial probe ultrasonography, soft tissue mammography, and metastatic workup including pelvi-abdominal ultrasonography, CXR, and bone scan to exclude any distant metastasis.
- Pathological studies such as FNAC, Core biopsy, and excisional biopsy were recorded regarding the histological type (intraductal carcinoma, intralobular carcinoma, or mixed), stage, grade, number of lymph nodes removed, and number of positive nodes.

\section{Methods:}

The patients are divided randomly into three groups:

Group A: This group included ten patients. In this group, after completing the modified radical mastectomy procedure, the Quilting technique was done by using fine absorbable sutures (vicryl 3/0), multiple alternating stitches $3 \mathrm{~cm}$ apart were taken in raws between the subcutaneous tissues of the skin flaps and the underlying muscles at various parts of the flap and also, at the wound edge. A closed suction drain of 2 limbs was used.

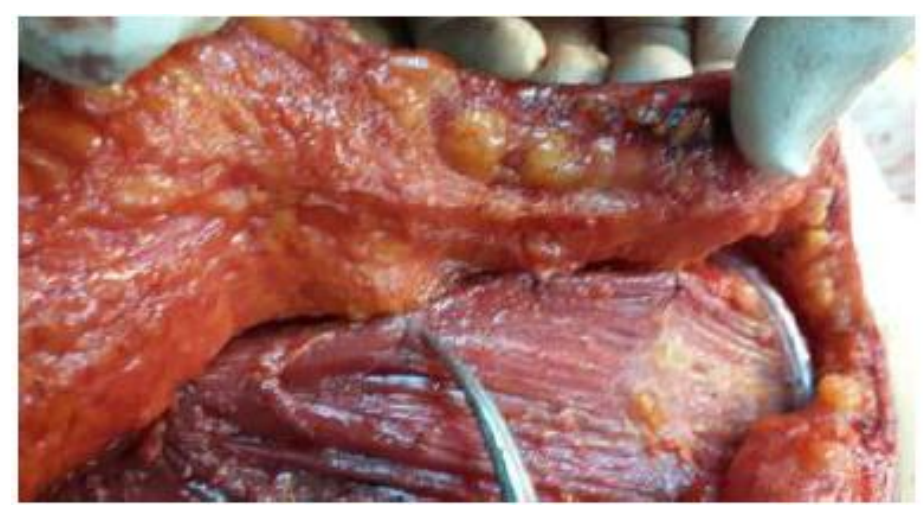

Figure (1): Fixation of the upper mastectomy flap to the underlying pectoralis major muscle.

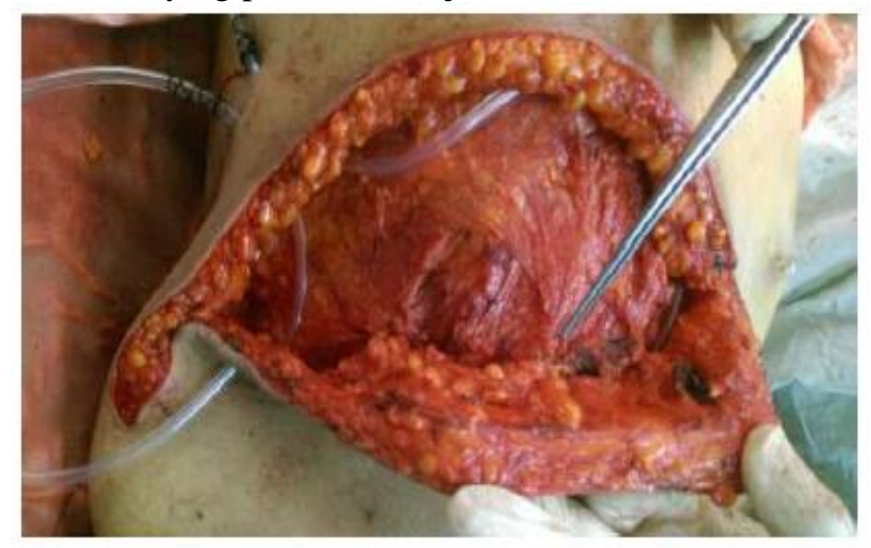

Figure (2): Fixation of the lower mastectomy flap to the pectoral muscles. 


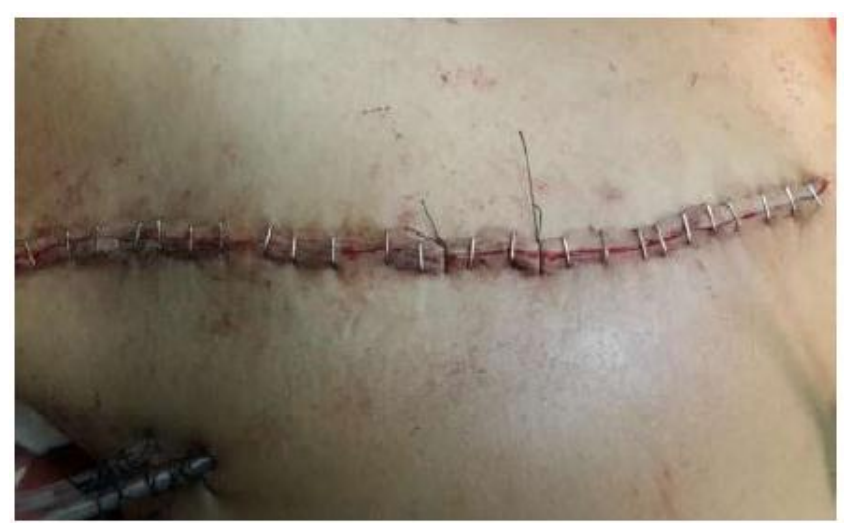

Figure (3): Mastectomy wound closure after flap

fixation.

Group B: This group included also ten patients. This group was submitted to restriction of shoulder mobility postoperatively to abolish the shearing movement of the skin flaps. The arm was immobilized for the first 7 days postoperatively, this was achieved by padding the axillary fossa with a bulk of cotton dressing, also tight dressing was applied to chest skin flaps, then the arm was adducted over the axillary fossa and a crepe bandage was wrapped around to fix them in place. A collar's cuff sling was used when the patient was out of bed, with the arm relaxed and the elbow flexed $90^{\circ}$, when the patient in bed, the arm was rested on a pillow, hand and wrist movements was allowed. Shoulder exercises started at the eighth postoperative day, movements of the shoulder were performed actively once a day under the supervision of a physiotherapist. All movements, specially anteflexion, abduction, horizontal abduction, and exorotation were carried out until the pain barrier was reached. All spontaneous movements and use of the arm during the remaining part of the day are allowed, provided pain did not happen.

Physiotherapeutic supervision was discontinued when shoulder function returned to its preoperative level. Physiotherapy at home was prescribed when ante-flexion had restricted more than $20^{\circ}$ or exo-rotation had restricted more than $10^{\circ}$. Shoulder function, abduction, exo-rotation with the humerus in a neutral position, and exo-rotation with the humerus in abduction, was measured before surgery, on the first day of shoulder movements, and at discharge. The first and late measurements were done with the contralateral shoulder as well. So, each patient had a "normal" standard. A closed suction drain of 2 limbs was used.

Group C: This group included also ten patients. In this group, was under the effect of administrations of tranexamic acid (cyklokapron) preoperative and postoperative. Tranexamic acid (1 gm I.V. - T.D.S.) was administrated for 24 hours preoperative and continued 5 days postoperative. A closed suction drain of 2 limbs was used.

\section{Ethical approval and written informed consent:}

Approval of the study was obtained from Aswan University's academic and ethical committee. Every patient signed informed written consent for the acceptance of the operation.

\section{Statistical design:}

The collected data were analyzed by computer using Statistical Package of Social Services version 24 (SPSS), Data were represented in tables and graphs, Continuous Quantitative variables e.g. age were expressed as the mean $\pm \mathrm{SD} \&$ median (range), and categorical qualitative variables were expressed as absolute frequencies (number) \& relative frequencies (percentage). Suitable statistical tests of significance were used after checked for normality. The results were considered statistically significant when the significant probability was less than $0.05(\mathrm{P}<0.05)$. $\mathrm{P}$-value $<0.001$ was considered highly statistically significant (HS), and P-value $\geq 0.05$ was considered statistically insignificant (NS).

\section{RESULTS}

Table (1): Demographic data of the studied post modified radical mastectomy cases $(\mathrm{N}=30)$.

\begin{tabular}{|l|c|c|}
\hline \multirow{2}{*}{ Demographic data } & \multicolumn{2}{|c|}{ Studied patients (N=30) } \\
\cline { 2 - 3 } & No. & \% \\
\hline Age (years) & \multicolumn{2}{|c|}{$49.6 \pm 8.46$} \\
\hline Mean \pm SD & \multicolumn{2}{|c|}{$45(40-68)$} \\
\hline Median (Range) & 19 & 63.3 \\
\hline Age & 11 & 36.7 \\
\hline Pre-menopausal &
\end{tabular}

This table shows that the mean age of the studied groups is $49.6 \pm 8.46$ years old, with a range from 40 to 68 years old. About 2/3 of the studied group are premenopausal (63.3\%), and $36.7 \%$ are Post-menopausal.

Table (2): Contributing factors acting for the development of seroma among post modified radical mastectomy cases $(\mathrm{N}=30)$.

\begin{tabular}{|l|c|c|}
\hline \multirow{2}{*}{ Item } & \multicolumn{2}{|c|}{ Studied patients } \\
\cline { 2 - 3 } & No. & \% \\
\hline Age & 6 & 31.5 \\
\hline Pre-menopausal (N=19) & 4 & 36.3 \\
\hline Post-menopausal (N=11) & 3 & 100.0 \\
\hline Obesity (N=3) & 4 & 100.0 \\
\hline Hypertension(N=4) & 0 & 0.0 \\
\hline Diabetes mellitus(N=2) & 5 & 55.6 \\
\hline Blood transfusion $(\mathbf{N = 9 )}$ & 5
\end{tabular}

Table (2) shows that $31.5 \%$ of the studied premenopausal females developed seroma and all of the obese and hypertensive patients developed seroma ( 3 out of 3 obese), ( 4 out of 4 hypertensive females),(3 out of 3 diabetics) respectively, while more than half 
of females with a positive history of blood transfusion (55.6\%) developed seroma after a modified radical mastectomy.

Table (3): Staging of cancer according to TNM classification and post modified radical mastectomy seroma formation among the studied cases $(\mathbf{N}=30)$.

\begin{tabular}{|c|c|c|c|c|}
\hline \multirow{2}{*}{\multicolumn{2}{|c|}{$\begin{array}{l}\text { Staging of } \\
\text { cancer }\end{array}$}} & \multirow{2}{*}{$\begin{array}{c}\begin{array}{c}\text { Total } \\
(\mathbf{N}=\mathbf{3 0})\end{array} \\
\text { No. }\end{array}$} & \multicolumn{2}{|c|}{$\begin{array}{l}\text { Seroma formation } \\
(\mathrm{N}=10)\end{array}$} \\
\hline & & & No. & $\%$ \\
\hline - & Stage I & 1 & 1 & 100.0 \\
\hline$\bullet$ & Stage II & 24 & 6 & 25.0 \\
\hline$\bullet$ & Stage III & 5 & 3 & 60.0 \\
\hline
\end{tabular}

Table (3) shows that $100 \%$ of the studied stage I developed seroma and $1 \backslash 4$ of the studied stage II patients developed seroma (6 out of 24) while about $3 / 5$ of females with cancer stage III $(60 \%)$ developed seroma after a modified radical mastectomy.

Table (4): Number of infiltrated $L N$ concerning post modified radical mastectomy seroma formation among the studied cases $(\mathrm{N}=30)$.

\begin{tabular}{|l|c|c|c|c|}
\hline \multirow{2}{*}{ Infiltrated LN } & \multicolumn{2}{|c|}{ Total (N=30) } & \multicolumn{2}{|c|}{$\begin{array}{c}\text { Seroma formation } \\
\text { (N=10) }\end{array}$} \\
\cline { 2 - 5 } & No. & $\%$ & No. & $\%$ \\
\hline $\begin{array}{l}\text { More than } \\
\text { 4 LN }\end{array}$ & 13 & 43.3 & 4 & 30.7 \\
\hline $\begin{array}{l}\text { Less than } 4 \\
\text { LN }\end{array}$ & 17 & 56.7 & 6 & 35.2 \\
\hline
\end{tabular}

Table (4) shows that less than half of the studied $(43.3 \%)$ had more than 4 lymph nodes infiltrated and seroma formation was found in $(30.7 \%$ \& $35.2 \%$ ) in cases with more than 4 infiltrated LNs and in cases with less than 4 infiltrated LNs respectively.

Table (5): Methods used to manage seroma formation post modified radical mastectomy.

\begin{tabular}{|l|c|c|}
\hline \multirow{2}{*}{\multicolumn{1}{|c|}{ Item }} & \multicolumn{2}{|c|}{$\begin{array}{c}\text { Seroma } \\
\text { formation } \\
(\mathbf{N = 1 0})\end{array}$} \\
\cline { 2 - 3 } & No. & $\%$ \\
\hline $\begin{array}{l}\text { Aspiration under complete } \\
\text { aseptic condition }\end{array}$ & $\mathbf{6}$ & $\mathbf{6 0 . 0}$ \\
\hline Two setting aspiration & 3 & 50.0 \\
\hline Three setting aspiration & 1 & 16.6 \\
\hline Five setting aspiration & 1 & 16.6 \\
\hline Eight setting aspiration & 1 & 16.6 \\
\hline Closed drainage system & 1 & 10.0 \\
\hline open drainage system & 3 & 30.0 \\
\hline
\end{tabular}

This table shows that $60 \%$ (6 out of 10 seroma) underwent Aspiration under complete aseptic condition and a closed drainage system and open drainage system were used in $(10 \%$ \& 30\%) respectively to manage seroma formation after modified radical mastectomy.

Table (6): Complications of different modalities of prevention of seroma formation post modified radical mastectomy among the studied groups.

\begin{tabular}{|c|c|c|c|c|c|c|c|c|}
\hline \multirow[t]{2}{*}{ Item } & \multicolumn{2}{|c|}{$\begin{array}{c}\text { Shoulder } \\
\text { immobilization } \\
(\mathbf{N}=10)\end{array}$} & \multicolumn{2}{|c|}{$\begin{array}{c}\text { Special flap } \\
\text { closure } \\
(\mathrm{N}=10)\end{array}$} & \multicolumn{2}{|c|}{$\begin{array}{c}\text { Tranexamic acid } \\
(\mathrm{N}=10)\end{array}$} & \multirow{2}{*}{$\begin{array}{l}\text { Chi- } \\
\text { square } \\
\text { test }\end{array}$} & \multirow[t]{2}{*}{ P-value } \\
\hline & No. & $\%$ & No. & $\%$ & No. & $\%$ & & \\
\hline \multicolumn{9}{|c|}{ Seroma formation } \\
\hline - $\quad$ Yes & 0 & 0.0 & 4 & 40.0 & 6 & 60.0 & \multirow[t]{2}{*}{8.4} & \multirow{2}{*}{$\begin{array}{l}\mathbf{0 . 0 1 5}^{*} \\
(\mathbf{S})\end{array}$} \\
\hline - $\mathrm{No}$ & 10 & 100.0 & 6 & 60.0 & 4 & 40.0 & & \\
\hline \multicolumn{9}{|c|}{ Shoulder stiffness } \\
\hline - Yes & 6 & 60.0 & 0 & 0.0 & 0 & 0.0 & \multirow[t]{2}{*}{15.00} & \multirow{2}{*}{$\begin{array}{l}\text { 0.000* } \\
\text { (HS) }\end{array}$} \\
\hline - $\mathrm{No}$ & 4 & 40.0 & 10 & 100.0 & 10 & 100.0 & & \\
\hline \multicolumn{9}{|c|}{ Wound infection } \\
\hline - $\quad$ Yes & 1 & 10.0 & 1 & 10.0 & 2 & 20.0 & \multirow[t]{2}{*}{0.576} & \multirow{2}{*}{$\begin{array}{c}0.749 \\
(\mathrm{NS})\end{array}$} \\
\hline - $\mathrm{No}$ & 9 & 90.0 & 9 & 90.0 & 8 & 80.0 & & \\
\hline \multicolumn{9}{|c|}{ Skin flap necrosis } \\
\hline - Yes & 0 & 0.0 & 0 & 0.0 & 1 & 10.0 & \multirow[t]{2}{*}{2.06} & \multirow{2}{*}{$\begin{array}{l}0.533 \\
(\mathrm{NS})\end{array}$} \\
\hline - $\mathrm{No}$ & 10 & 100.0 & 10 & 100.0 & 9 & 90.0 & & \\
\hline
\end{tabular}

Test: chi-square test P-value $<0.05$ is significant(S) NS=non-significant

This table shows that no seroma formation occurs with shoulder immobilization, while seroma formation was found in (40\% \& 60\%) in groups managed by special flap closure and tranexamic acid respectively with statistically significant difference $(\mathrm{p}=0.015)$, and shoulder stiffness occurs in $60 \%$ of shoulder immobilization group with statistical significant difference, $(\mathrm{p}=0.000)$, while there is no difference between 3 groups regarding occurrence of wound infection or skin flap necrosis. 
Table (7): Different modalities of prevention of seroma formation post modified radical mastectomy regarding the amount of drainage and time of drain removal among the studied groups.

\begin{tabular}{|c|c|c|c|c|}
\hline Item & $\begin{array}{c}\begin{array}{c}\text { Shoulder } \\
\text { immobilization } \\
(\mathrm{N}=10)\end{array} \\
\end{array}$ & $\begin{array}{l}\text { Special flap closure } \\
(\mathbf{N}=10)\end{array}$ & $\begin{array}{l}\text { Tranexamic } \\
\text { acid }(N=10)\end{array}$ & p-value \\
\hline \multicolumn{5}{|c|}{ Day of drain removal } \\
\hline Mean \pm SD & $6.56 \pm 2.4$ & $5.750 \pm 1.94$ & $10.2 \pm 3.91$ & $\begin{array}{c}\text { 0.001* }^{*} \\
\text { (HS) }\end{array}$ \\
\hline \multicolumn{5}{|c|}{ Total drained fluid } \\
\hline Mean \pm SD & $905.6 \pm 209$ & $875.5 \pm 372.9$ & $1767.5 \pm 830.5$ & $\begin{array}{c}\text { 0.001* }^{*} \\
\text { (HS) }\end{array}$ \\
\hline \multicolumn{5}{|c|}{ Drained fluid in last 3 days } \\
\hline Mean \pm SD & $155.67 \pm 90.8$ & $135.75 \pm 40.95$ & $271.5 \pm 139.6$ & $\begin{array}{c}\mathbf{0 . 0 1 0} * \\
(\mathbf{S})\end{array}$ \\
\hline \multicolumn{5}{|c|}{ Drained fluid last day } \\
\hline Mean \pm SD & $35.22 \pm 10.5$ & $32.75 \pm 8.95$ & $47.25 \pm 16.89$ & $\begin{array}{c}\mathbf{0 . 0 3 5}^{*} \\
(\mathbf{S})\end{array}$ \\
\hline
\end{tabular}

This table shows that the special flap closure group and shoulder immobilization group are significantly lower regarding the day of drain removal, totally drained fluids, amount of drained fluid in the last 3 days before drain removal and amount drained the last day.

\section{DISCUSSION}

This study was done on 30 patients with demographic as following; The mean age of the studied groups is $49.6 \pm 8.46$ years old, with a range from 40 to 68 years old, $63.3 \%$ of patients were premenopausal and $36.7 \%$ of patients were postmenopausal, $10 \%$ of the studied group was obese, $13 \%$ were hypertensive and DM was found in $6 \%$ of patients. Thirty percent of them have a positive history of blood transfusion.

In this study, there was no statistical significance in menopause state in seroma formation as post modified radical mastectomy was developed in $31.5 \%$ of patients pre-menopausal, $36 \%$ of patients post-menopausal, on the other hand, there was a significant statistical difference in obesity and the hypertensive state as $100 \%$ in both obese and hypertensive patients developed seroma, $55.6 \%$ in patients with a history of blood transfusion, and there was no statistical significance in the diabetic state as $0 \%$ in patients with DM developed seroma.

Akinci et al. ${ }^{(7)}$ made a thesis on 40 patents, $27.5 \%$ of patients developed seroma after mastectomy; Patients with hypertension were more likely to develop seroma after mastectomy $50 \%$ of patients with hypertension. But no such difference was found in patients with diabetes mellitus. No differences in the incidence of seroma formation were found between the patients with 20 lymph nodes or less taken.

Kuroi et al. ${ }^{(8)}$ found that DM found no significant association with diabetes and seroma formation. Hypertension was found as a risk factor for seroma, which was reported by Loo and Chow (9) that was correlated with this study.

Seroma formation post modified radical mastectomy among the studied cases in this study showed a statistical difference between different stages of breast cancer as Stage I included 1 patient with the formation of seroma (100\%). Stage II includes 24 patients with 6 patients (25\%) developed seroma. Stage III includes 5 patients with 3 patients (60\%) developed seroma.

On the other hand Hoefer et al. ${ }^{(10)}$, Kumar et al. ${ }^{(11)}$, and Bland et al. ${ }^{(12)}$ reported that staging of cancer breast didn't affect post mastectomy seroma that wasn't correlated with this study.

In this study seroma formation post modified radical mastectomy according to the number of infiltrated LN more or less than 4 lymph nodes. There was no statistical difference between 2 groups as the results showed that more than $4 \mathrm{LN}$ was found in 13 patients $(43.3 \%), 30.7 \%$ were developed seroma. Less than $4 \mathrm{LN}$ was found in 17 patients (56.7\%), 35.2\% were developed seroma.

Ebrahimifard ${ }^{(13)}$ had correlated results with this study as he reported that the number of lymph nodes involved had no statistically significant difference in seroma formation (P-value $=0.145)$. Also, Wolde et al. ${ }^{(14)}$ and Khater et al .

(1) reported that there was no statistically significant difference in the number of positive lymph nodes removed in MRM. Akinci et al. ${ }^{(7)}$ found that there were no differences in the incidence of seroma formation between the patients with either no 
metastasis or up to 3 metastatic lymph nodes and the patients with 4 or more metastatic lymph nodes.

Different modalities were done in the management of seroma formation post modified radical mastectomy in this study as; $60 \%$ underwent aspiration under complete aseptic condition, closed drainage system $10 \%$, and open drainage system $30 \%$.

Kuroi et al. ${ }^{(8)}$ reported that single or multiple aspirations under complete aseptic conditions, closed drainage system, and open drainage system are different methods in the treatment of seroma.

Complications of different modalities of prevention of seroma formation post modified radical mastectomy among the studied groups in this study included; Seroma formation which was significantly decreased in Shoulder immobilization $0 \%$, then Special flap closure $40 \%$, then Tranexamic acid $60 \%$ which had P-value 0.015 . On the other hand complications of prevention of seroma like. Shoulder, stiffness was found specific to Shoulder immobilization (60\% of cases) and not found in other groups, wound infection, and Skin flap necrosis was found not specific for any group with $\mathbf{P}$ value were 0.749 and 0.533 respectively.

Similar results obtained by Ozaslan et al . (15) in 100 patients study (50 in each group) where the seroma rates in the control group were 12 patients of total 50 patients $(24 \%)$ and 6 patients of total 50 patients in the study group (12\%) (P-value $<0.05)$. This was in line with Sakkary ${ }^{(16)}$ who described in a similar study (20 patients per each group) that the incidence of seroma formation was $20 \%$ in the intervention group versus $50 \%$ in the control group $(\mathbf{P}$-value $=0.028)$. A similar figure was reported by Khater et al. ${ }^{(1)}$ who described the incidence of seroma in the suture group $20 \%$ versus $78.6 \%$ in the control group ( $\mathbf{P}$-value $<0.001)$. And Arafa et al. ${ }^{(17)}$ reported that the flap fixation group showed a significantly lower frequency of seroma formation compared to the control group (P-value $=$ 0.028). There was no significant difference regarding wound infection in both groups $(\mathbf{P}$-value $=0.29)$, Also no significant difference regarding skin flap necrosis in both groups $(\mathbf{P}$-value $=0.31)$.

This study showed that the special flap closure group and shoulder immobilization group are significantly lower regarding the day of drain removal 3-9 days (P-value 0.001), totally drained fluids (P-value 0.001), amount of drained fluid in the last 3 days before drain removal (P-value 0.01) and amount drained the last day (P-value 0.035).

Akinci et al. ${ }^{(7)}$ reported that when a drain was required for $>7$ days, seroma formed more often $(36.4 \%)$ as compared to when the drain stayed for a shorter time $(5.6 \%) \quad(\mathbf{P}$-value $=0.011)$.
Andeweg et al. ${ }^{(18)}$ also found that early removal of drain had higher seroma incidence.

Sakkary ${ }^{(16)}$ reported that there was a decrease in total drainage volume with flap fixation (P-value $<0.001)$. In a recent study done by Wolde et al. (14), there was a mean decrease in total drainage volume from $2649.79 \mathrm{ml}$ in the control group to $869.29 \mathrm{ml}$ in the intervention group (Pvalue $=0.125)$. Similar results obtained by Khater et al. $^{(1)}$ where the quilting technique significantly reduced the mean duration of drainage from 11 days in the control group to 9 in the intervention group $(\mathbf{P}$-value $<0.001)$.

Arafa et al. ${ }^{(17)}$ reported that the drain was removed in a highly significant shorter time compared to the control group. In the non-fixation group, the removal time of the drains was ranged 620 days, whereas it was ranged 3-10 days in the fixation group (P-value $<0.001$ ), also the total amount of fluid drained was highly significantly lower in the flap fixation group $(\mathbf{P}$-value $<0.001)$. During the last 3 days before drain removal, the amount of drained fluid was highly significantly lower in the flap fixation group (P-value < 0.001). The amount drained in the last day was significantly lower in the flap fixation group $(\mathrm{p}=0.002)$.

On the other hand, Kelley et al. ${ }^{(19)}$ found that there is no difference between early and late removal of the drain.

\section{CONCLUSION AND RECOMMENDATIONS}

The mastectomy flap fixation technique is a valuable procedure that significantly decreases the incidence of seroma formation, and reduces the duration and amount of drained fluid. Therefore we recommend fixation of skin flaps to the pectoral muscle as a routine step at the end of any mastectomy. However, it should be tried on a much wider scale to prove its validity.

\section{REFERENCES}

1. Khater A, Elnahas W, Roshdy $S$ et al. (2015): Evaluation of the Quilting Technique for Reduction of Postmastectomy Seroma: A Randomized Controlled Study. International Journal of Breast Cancer, 287398: 1-6.

2. Ouldamer L, Bonastre J, Brunet-Houdard S et al. (2016): Dead space closure with quilting suture versus conventional closure with drainage for the prevention of seroma after mastectomy for breast cancer (QUISERMAS): protocol for a multicentre randomized controlled trial: Table 1. BMJ., 6(4): 99103.

3. Pantelides N, Down S, Pereira J (2014): Techniques to reduce seroma formation after mastectomy and axillary clearance: Current trends amongst UK breast surgeons. European Journal of Surgical Oncology, 40(5): 642-47. 
4. Troost M, Kempees C, Roos M (2015): Breast cancer surgery without drains: No influence on seroma formation. International Journal of Surgery, 13:170174.

5. Zaidi S, Hinton C (2017): Breast cancer surgery without suction drainage and impact of mastectomy flap fixation in reducing seroma formation. European Journal of Surgical Oncology, 43(5): 32-37.

6. Chatterjee S, Ryntathiang I (2015): A prospective study on delayed shoulder exercises in reducing seroma formation after a modified radical mastectomy. Hellenic Journal of Surgery, 87(2): 165168.

7. Akinci M, Cetin B, Asian S et al. (2009): Factors affecting seroma formation after mastectomy with full axillary dissection. Acta Chirurgica Belgica, 109(4): 481-483.

8. Kuroi K, Shimozuma K, Taguchi T et al. (2006): Evidence-based risk factors for seroma formation in breast surgery. Jpn J Clin Oncol., 36:197-206.

9. Loo W, Chow $L$ (2007): Factors predicting seroma formation after mastectomy for Chinese breast cancer patients. Indian J Cancer, 44: 99-103.

10. Hoefer J, DuBois J, Ostrow L et al. (1990): Wound complications following modified radical mastectomy: an analysis of perioperative factors. The Journal of the American Osteopathic Association, 90(1): 47-53.

11. Kumar S, Lal B, Misra M (1995): Post-mastectomy seroma: a new look into the etiology of an old problem. Journal of the Royal College of Surgeons of Edinburgh, 40(5): 292-294.
12. Bland K, Chang H, Copeland E (2018): Modified radical mastectomy and simple mastectomy. In The Breast (Fifth Edition), Pp. 443-461.

13. Ebrahimifard F (2016): Effect of One versus Two Drain Insertion on Postoperative Seroma Formation after Modified Radical Mastectomy. Novelty in Biomedicine, 4(2): 45-50.

14. Wolde B, Frits J, Mariel E et al. (2014): Quilting Prevents Seroma Formation Following Breast Cancer Surgery: Closing the Dead Space by Quilting Prevents Seroma Following Axillary Lymph Node Dissection and Mastectomy. Ann Surg Oncol., 21:802-807.

15. Ozaslan C, Yilmaz K, Ozdogan T et al. (2010): Effect of mechanical closure of dead space on seroma formation in modified radical mastectomy. Turk $\mathrm{J}$ Med Sci., 40(5): 751-755.

16. Sakkary M (2012): The value of mastectomy flap fixation in reducing fluid drainage and seroma formation in breast cancer patients. World Journal of Surgical Oncology, 10(1): 8-13.

17. Arafa A, Fayek F, Awad J (2019): Efficacy of mastectomy flap fixation in minimizing seroma formation after breast cancer surgery. Egypt J Surg., 38:656-61.

18. Andeweg $\mathrm{C}$, Schriek M, Heisterkamp J et al. (2011): Seroma formation in two cohorts after axillary lymph node dissection in breast cancer surgery: does timing of drain removal matter?. The Breast Journal, 17(4): 359-364.

19. Kelley T, Thomson D, Furniss D (2012): When should axillary drains be removed post axillary dissection? A systematic review of randomized control trials. Surg Oncol., 21(4): 247-251. 